\title{
Effects of Particle Conductivity on the Fe-Si co-deposition Process
}

\author{
Qiong Long ${ }^{1,2 *}$, Yunbo Zhong ${ }^{2}$, Yujiao $\mathrm{Wu}^{1}$, Yingzhe Zhang $^{1}$ \\ ${ }^{1}$ Guizhou Key Laboratory for preparation of light metal materials, Guizhou Institute of Technology \\ Guiyang 550003, China \\ ${ }^{2}$ State Key Laboratory of Advanced Special Steel, College of Materials Science and Engineering, \\ Shanghai University, Shanghai 200072, PR China \\ *E-mail: qiong12030@163.com
}

doi: $10.20964 / 2018.12 .13$

Received: 14 August 2018 / Accepted: 23 September 2018 / Published: 5 November 2018

Composite iron deposits containing non-conductivite Si particles and conductive Si-Fe alloy particles with an average size of $1 \mu \mathrm{m}$ were prepared in circulating solution, the effects of particle conductivity on the co-deposition process of particles were investigated. The results show that high conductivity contributed to the co-deposition process of particles into the composite coatings, and in a mode of "cladding" for the co-deposition of conductive $\mathrm{Si}-\mathrm{Fe}$ particles, while that for non-conductive $\mathrm{Si}$ particles was "embedding" mode. At the same time, with increasing the conductivity, the co-deposition process of particles was obviously deviate from the Guglielmi model. A possible mechanism on the forming process was discussed.

Keywords: Fe-Si coating; Electrodeposition;Particle; Conductivity; Co-deposition

\section{FULL TEXT}

(C) 2018 The Authors. Published by ESG (www.electrochemsci.org). This article is an open access article distributed under the terms and conditions of the Creative Commons Attribution license (http://creativecommons.org/licenses/by/4.0/). 